\title{
Fugitive methane emissions from the natural gas distribution network of Titas Gas and the environmental risks
}

\author{
P. C. Mandal ${ }^{1}$, S. Chowdhury ${ }^{1}$ \& S. M. Morshed $^{2}$ \\ ${ }^{1}$ Department of Chemical Engineering, \\ Universiti Teknologi PETRONAS, Malaysia \\ ${ }^{2}$ Titas Gas Transmission and Distribution Co. Ltd., Bangladesh
}

\begin{abstract}
The pipeline quality natural gas of Titas Gas (TG) contains approximately $96.12 \%$ (mol/mol) methane. Fugitive emissions are unintentional leaks emitted from sealed surfaces or leaks from underground pipelines resulting from corrosion or faulty connections. Methane is a potent greenhouse gas effect next to carbon dioxide. Reducing methane emission is an essential step toward reducing global warming. Inventory data on methane emission from natural gas transmission and distribution system of TG is absent in open literature. The objective of this paper is to explore the problems generated by gas leaks and to quantify the leaked methane gas from the above-ground facilities of the existing system of TG. Economic and environmental impacts for such fugitive emissions are also critically examined. In this study, leaks were detected using soap screening techniques and the Gasurveyor 500 series instrument. Leaked gas was quantified using either the Hi-Flow gas sampler or a bagging measurements system. The results show that approximately $2.1 \%$ of the purchased gas is leaked from the above-ground facilities of TG. Total estimated emission is approximately 4.214 $\mathrm{MMTCO}_{2} \mathrm{e}$ per year that is approximately $4.74 \%$ of the total amount of methane emission from human activities and industrial methane production in Bangladesh during the year 2000. TG can save approximately USD 14.67 million per year by stopping these emissions. It is now a vital issue for TG to seize gas leakages for attaining the international standard of climate mitigation as well as upholding the image of TG.
\end{abstract}

Keywords: methane emission, gas leak, greenhouse effect, global warming, climate mitigation. 


\section{Introduction}

The gases present in the atmosphere which can prevent heat from escaping from the earth are known as greenhouse gases (GHGs). The Kyoto Protocol, the first agreement between nations to mandate country-by-country reductions in GHG emissions, covers six greenhouse gases: carbon dioxide, methane, nitrous oxide, hydrofluorocarbons, perfluorocarbons and sulphur hexafluoride [1]. Out of these six gases, three are of primary concern as they are closely associated to human activities. If the amount of these gases increases in the atmosphere due to various human activities, like, burnings of fossil fuels, etc. earth temperature will increase. Scientists have named this phenomenon "Global Warming" and the associated changes to the atmosphere are known as "Climate Change". Scientists have detected various indication of this change likes rising sea level, changing rain pattern, occurrence of extreme events such as cyclone, floods, and droughts. It is possible to boost the process of global warming by undertaking a variety of measure [2], like, switching from coal to natural gas, using more efficient devices in industrial and commercial sectors, using renewable energy, preventing release of methane gas from landfill and natural gas production, transmission and distribution system, etc. Though Bangladesh is a low carbon dioxide emitting country, there is no relief from the effects of Global Warming because 1.5 meter rise in sea level would inundate an area of 22,000 square kilometres of Bangladesh [2] which is approximately $15 \%$ of total area of Bangladesh (total area of Bangladesh is 147,570 square kilometres).

Literature revealed that natural gas is cleaner than coal when used for electricity, and cleaner than diesel fuel when used for transportation. According to theory, burning natural gas for electricity emits about half the carbon dioxide that we get from burning coal. But if the methane leak rate from that entire natural gas infrastructure starts creeping up past 3.2 percent, recent Proceedings of the National Academy of Sciences (PNAS) study found, and then suddenly natural gas starts to lose its climate advantage [3]. The occurrence of gas leak-related incidents was studied by several organizations which published statistics on the reported incidents. One of these studies, made on the sub-sea pipeline systems [4], states that, between 1996 and 2006, a number of 80 pipeline rupture incidents were reported in the Gulf of Mexico and Pacific areas. Based on data gathered in this report, the calculated probability of a catastrophic incident, for the specified area, is 0.43 incidents per year. Another survey [5], which focuses on the risks of pipeline transportation, covers incidents that occurred in Europe and on the American continent presenting the main causes of pipeline failure. According to this report, in the province of Alberta, Canada alone, there have been 1326 reported gas leaks in the 2001-2005 periods. A different report shows that large pipelines (i.e. with a length of 800 miles or more) can expect at least one reportable leak-related incident per year [6]. This evidence indicates that the risk of incidents caused by gas leaks is substantial despite the great variety of leak detection methods available and serves as motivation of work.

Titas Gas (TG), the premier gas distribution company of Bangladesh, transmits natural gas from the gas fields to different areas and to distribute the same to the 
consumers in power, fertilizer, industrial, captive power, commercial, seasonal and domestic categories [7] of its franchise areas of Dhaka, Gazipur, Narayanganj, Narshindi, Brahmanbaria, Jamalpur, Sherpur, Netrokona, Kishoreganj, Tangile, Mymenshingh, Netrokona and Munshiganj district. TG transmits and distributes around $74 \%$ of country's total consumption. Presently, TG's system is receiving gas from Titas, Habiganj, Narsingdi \& Bakhrabad Gas Fields under Bangladesh Gas Fields Co. Ltd. and from Rashidpur, Kailashtila, Beanibazar Gas Fields under Sylhet Gas Fields Co. Ltd. and Jalalabad Gas Field of Oxydental/Unicol. TG is $75 \%$ owned by the government, with the remainder owned by public shareholders. It serves 1,535,592 customers (1,519,124 domestic; 10,530 commercial; and 5,938 industrial including CNG, power, fertiliser) and accounts for more than $70 \%$ of gas distribution in Bangladesh [8].

Mandal in 2013 [8] discovered that TG currently has no advanced leak detection and repair (LDAR) program to detect, measure and repair leaks like developed country. Inefficient biological methods are used to detect gas leakage. All under-ground distribution networks and facilities in the TG are cathodically protected. Though TG has a cathodic protection (CP) maintenance schedule, it does not have planned LDAR schedule. Gas leak repairing activities are implemented only to meet safety requirement of Prakitik Gas Nirapatta Bidhimala, 1991-revised in 2003 [9]. These regulations are failed to provide exact safety specification. The company operates emergency team dedicated 24 hours a day to cover the emergency situations (e.g. customer call-outs). Thus existing procedures are only detecting a minority of leaks occurring in the system. It is no doubt that the system has a lot of leakages, most of them are undetected. TG can not only fail to detect all leakages found in their systems but also fail to quantify the same.

The objective of this paper is to explore the problems generated from gas leak and quantify the leaked methane gas from the above ground facilities of the existing system of TG. In addition, economic and environmental impacts for such fugitive emissions are also critically examined.

\section{Materials and methods}

\subsection{Leak detection technology}

Leak detection and repair have become increasingly critical to the safe and reliable delivery of gas and to protecting the environment. Different leak detection methods ranging from manual inspection to advanced satellite based hyperspectral imaging are applied to monitor the integrity of a gas pipeline [8, 10]. Broadly speaking they can be classified into three categories as biological methods, nonoptical methods and optical methods [8]. In this study, leaks were detected using soap screening and catalytic oxidation/thermal conductivity detectors, Gasurveyor 500 series instrument, a most flexible range of gas detectors developed by Gas Measurement Instruments Ltd. (GMIL).

Soap screening technique (fig. 1(a)) is used to detect the exact location [11] of a leak on an exposed gas pipe, on the riser, on the meter, on valves and piping joints. A soap solution specifically designed for gas pipelines is brushed or sprayed 
on and the location of bubbling indicates leakage [8]. The Gasurveyor ${ }^{\mathrm{TM}} 500$ Series (fig. 1(b)) made by GMIL, United Kingdom is a highly flexible, electronic portable gas detector designed as per latest standards and is certified for use in hazardous areas. The detector has liquid-crystal display (LCD) screen with automatic backlighting, audio, visual and fault alarms and are one of the state-ofthe-art gas detectors.

(a)

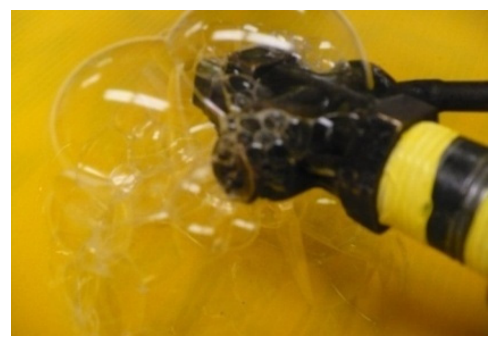

(b)

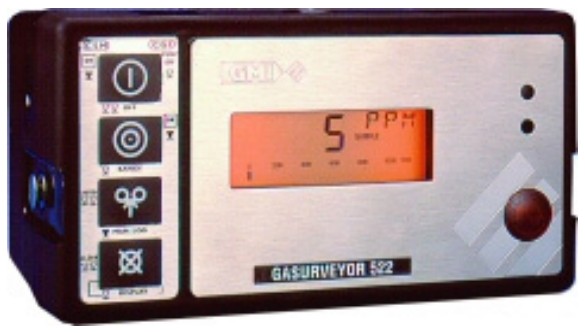

Figure 1: (a) Soap screening technique, (b) GMI Gasurveyor 500 Series.

\subsection{Leak measurement technology}

Two well-known leak measurement technologies, Hi-Flow gas sampler, a portable device developed by Gas Research Institute (GRI), and bagging measurements technology were used in this study. Bagging measurements (fig. 2(a)) are accurate but are too expensive and time consuming to measure every leak at a facility. In this method, the leaking component is wrapped with a non-permeable material (such as Tedlar or Mylar) and a clean purge gas (such as nitrogen) sweeps through the enclosure at a measured flow rate. Vacuum bagging may also be performed. For the case of methane the leak rate from the component can be calculated from the purge flow rate through the enclosure and the concentration of methane in the outlet stream as follows:

$$
Q_{\mathrm{CH}_{4}}=F_{\text {Purge }} \times C_{\mathrm{CH}_{4}},
$$

where, $Q_{\mathrm{CH}_{4}}=$ leak rate of methane from the enclosed component (scfm); $F_{\text {Purge }}=$ the purge flow rate of the clean air or nitrogen (scfm) and $C_{\mathrm{CH}_{4}}=$ the measured concentration of methane in the exit flow (\%)

The Hi-Flow gas sampler (fig. 2(b)) supplied by Heath Consultants were used. It captures all the emissions from a leaking component to accurately quantify leak emissions rates. Leak emissions, plus a large volume sample of the air around the leaking component, are pulled into the instrument through a vacuum sampling hose. A dual-element hydrocarbon detector (catalytic-oxidation/thermalconductivity) measures hydrocarbon concentrations in the captured air stream ranging from 0.01 to 100 percent. Sample measurements are corrected for the ambient hydrocarbon concentration, and mass leak rate is calculated by 
multiplying the flow rate of the measured sample by the difference between the ambient gas concentration and the gas concentration in the measured sample. HiFlow samplers' measure leak rates up to 10.5 cubic feet per minute, with the accuracy of calculated leak rate of $\pm 5 \%$. The leak flow rate of natural gas is calculated as follows:

$$
Q_{\text {Gas }}=F_{\text {Sample }} \times\left(C_{\text {main }}-C_{\text {background }}\right),
$$

where, $Q_{\text {Gas }}=$ leak rate of natural gas from the leaking component ( $1 / \mathrm{min}$ of scfm), $F_{\text {Sample }}=$ the sample flow rate of the high flow rate sampler $(1 / \mathrm{min}$ of $\mathrm{scfm})$, $C_{\text {main }}=$ the concentration of natural gas in the sample flow (\%) and $C_{\text {background }}=$ the concentration of natural gas in the background (\%).

(a)

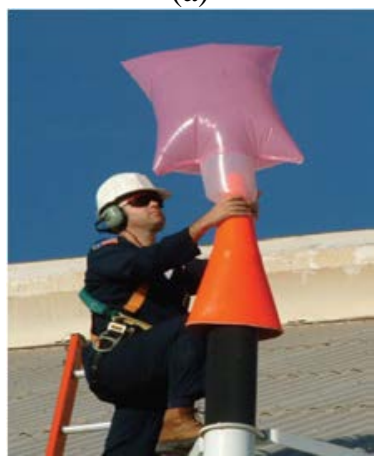

(b)

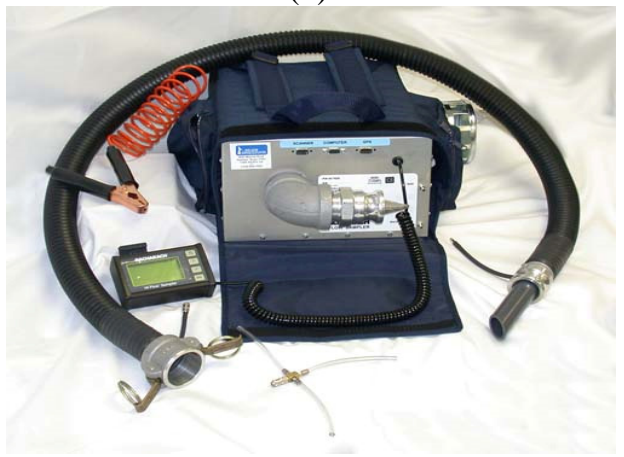

Figure 2: (a) Bagging measurements technique, (b) Hi-Flow sampler.

\section{Results and discussion}

This paper is organized as follows. First, atmospheric methane sources and sinks are described. Second, sources of gas leak are identified. Third, volumes of gas leak from the above ground facilities of TG are quantified. Finally, economic and environmental impacts for such fugitive emission are also critically examined

\subsection{Atmospheric methane sources and sinks}

Carbon dioxide $\left(\mathrm{CO}_{2}\right)$ is the primary and methane $\left(\mathrm{CH}_{4}\right)$ is the secondary greenhouse effect gas. Carbon dioxide currently makes up roughly 400 ppm (equivalent to $0.04 \%$ ) of earth's atmosphere and is increasing about $2 \mathrm{ppm}$ per year [12]. Though atmospheric concentrations of methane are much lower than that of carbon dioxide, totalling less than 2 ppm [12], its global warming potential (GWP) is 25 times higher than that of $\mathrm{CO}_{2}$ over a 100-year time horizon [13, 14], and even higher on a shorter time span (table 1). The composition of natural gas [15] of TG at Demra City Gate Station (CGS) is shown in table 2. It is no doubt that natural gas is composed primarily of methane. 
Table 1: Global warming potentials for greenhouse gases [13].

\begin{tabular}{|c|c|c|c|c|c|}
\hline \multirow[t]{3}{*}{ Species } & \multirow{3}{*}{$\begin{array}{l}\text { Life } \\
\text { time } \\
\text { (years) }\end{array}$} & \multicolumn{4}{|c|}{$\begin{array}{l}\text { Global Warming Potential, GWP } \\
\text { (Time Horizon) }\end{array}$} \\
\hline & & $\mathrm{SAR}^{*}$ & FAR $†$ & FAR† & FAR $\dagger$ \\
\hline & & $100-\mathrm{yr}$ & 20-yr & 100-yr & 500-yr \\
\hline Carbon dioxide $\left(\mathrm{CO}_{2}\right)$ & Variable & 1 & 1 & 1 & 1 \\
\hline Methane $\left(\mathrm{CH}_{4}\right)$ & 12 & 21 & 72 & 25 & 7.6 \\
\hline Nitrous oxide $\left(\mathrm{N}_{2} \mathrm{O}\right)$ & 114 & 310 & 289 & 298 & 153 \\
\hline Hydrofluorocarbons (HFCs) & & & & & \\
\hline e.g. HFC-23 & 270 & 11,700 & 12,000 & 14,800 & 12,200 \\
\hline Perfluorocarbons (PFCs) & & & & & \\
\hline e.g. Perfluomethane $\left(\mathrm{SF}_{4}\right)$ & 50,000 & 6,500 & 5,210 & 7,390 & 11,200 \\
\hline Sulphur hexafluoride $\left(\mathrm{SF}_{6}\right)$ & 3,200 & 23,900 & 16,300 & 22,800 & 32,600 \\
\hline
\end{tabular}

Table 2: Gas composition of natural gas at Demra CGS of TG [15].

\begin{tabular}{lrr}
\hline & \% Mole & $\% \mathrm{Wt}$ \\
\hline Nitrogen & 0.337 & 0.558 \\
Carbon dioxide & 0.331 & 0.861 \\
Methane & 96.120 & 91.125 \\
Ethane & 2.157 & 3.833 \\
Propane & 0.521 & 1.358 \\
i-Butane & 0.154 & 0.528 \\
n-Butane & 0.100 & 0.343 \\
i-Pentane & 0.050 & 0.215 \\
n-Pentane & 0.038 & 0.159 \\
Hexanes & 0.097 & 0.480 \\
Heptanes+ & 0.095 & 0.540 \\
\hline Total & \multicolumn{3}{c}{100} \\
\hline Temperature & \multicolumn{3}{c}{100} \\
Pressure & $75^{\circ} \mathrm{F}$ & \\
SG & $160 \mathrm{Psig}$ & \\
Real Gas Density & $0.5842 \mathrm{at} 15^{\circ} \mathrm{C}, 101.325 \mathrm{kPa}$ & \\
Mole Weight & $0.7177 \mathrm{~kg} / \mathrm{m}^{3}$ & \\
Compressibility & 16.9223 & \\
Higher Heating Value & 0.9975 & $\left.\mathrm{MJ} / \mathrm{sm}^{3}\right)$ \\
Lower Heating Value & $1044.6672 \mathrm{BTU} / \mathrm{SCF}(38.9212$ & \\
\hline
\end{tabular}

Atmospheric methane sources that are displayed in fig. 3 can be grouped into two categories: biogenic methane sources and non-biogenic methane sources. Biogenic sources contain $\mathrm{CH}_{4}$-generating microbes (methanogens), and comprise anaerobic environments. Methane is also produced by the incomplete combustion of biomass and soil carbon during wildfires, and of biofuels and fossil fuels known as Pyrogenic process. Non-biogenic methane is produced through Thermogenic 
process. In this process, methane is formed over millions of years through geological processes. Atmospheric methane is removed (i.e. converted to less harmful products) by a range of chemical and biological processes occurring in different regions of the atmosphere. These include tropospheric oxidation, stratospheric oxidation and uptake by soils. The predominant mechanism for removal of methane from the earth's atmosphere is oxidation within the troposphere by the hydroxyl radical $(\mathrm{OH})$. Approximately $90 \%$ of the atmospheric methane is oxidized in the troposphere. The remaining part is oxidized in the stratosphere at $10-15 \mathrm{~km}$ altitude where, except oxidation by $\mathrm{OH}$ radical, reactions of methane with $\mathrm{Cl}$ and $\mathrm{O}\left({ }^{1} D\right)$ radicals are important.

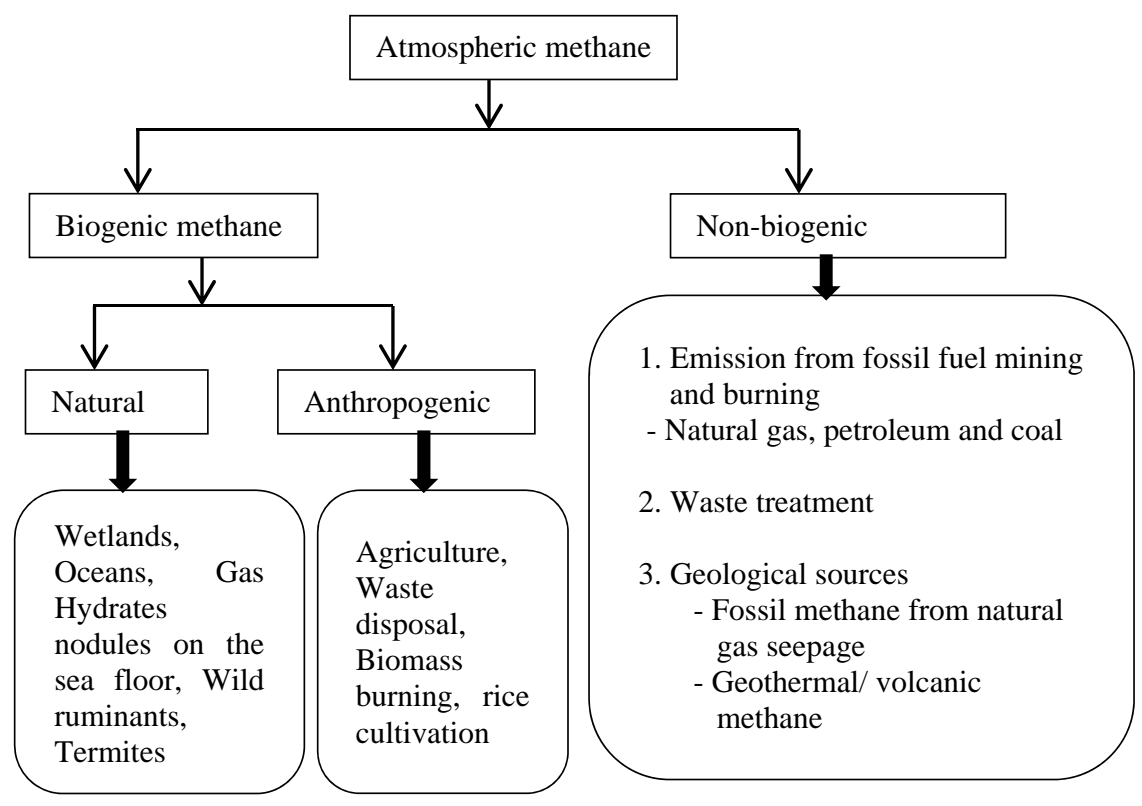

Figure 3: Sources of atmospheric methane.

\subsection{Gas leakage}

Natural gas releases to the atmosphere through fugitive, vented and combusted emissions. Fugitive emissions are unintentional leaks steadily from pipeline and system components (such as compressor seals, pump seals, valve packing and flange gaskets). Vented emissions are intentional unsteady state releases from equipment blow-down for maintenance, releases from emergency depressing from safety valves and station emergency blow-down, direct venting of gas used to power equipment (such as pneumatic valves), or accidental releases due to mishaps (such as pipeline dig-ins). Combusted emissions refer to methane that 
enters the atmosphere due to the incomplete combustion of natural gas, such as methane in compressor engine exhaust, methane from flare stacks and burners.

Most of the pipes installed worldwide prior to the 1950s were cast iron [16] and cast iron distribution pipelines experienced potential leakage around the world. Greenpeace (GP) [17] study revealed that approximately 5.3 to 10.8 percent of the gas flowing through Britain's natural gas pipes is leaking each year. The EPA in 1997 [18] estimated that approximately 1.4 percent $( \pm 0.5 \%)$ of all gas that travels through pipes in the US was emitted. Of all the methane released by industry in US, $20 \%$ of methane comes from the natural gas sector. In the same report, the EPA stated that of the methane released by the natural gas industry, $37 \%$ comes from transmission/ storage, $24 \%$ comes from distribution and $27 \%$ during production. USEPA estimates place global leakage of methane at 3 trillion cubic feet annually [19], or 3.2\% of global production. Howarth et al. in 2012 [20] have calculated that 2.2 to 3.8 per cent of shale gas leaks out at the well site and an additional 1.4 to 3.6 per cent leaks during transport, storage and distribution.

Thousands of unreported leaks are turning up under the underground gas pipeline of TG. Leaks in the distribution system were caused by normal component wear, thermal and vibrational stresses and seasonal expansion/contraction cycling from ambient air temperature changes. Natural gas leaks occurred through various sources including, ball/gate/plug valves, flanges, and connectors. Many of these components were not routinely checked under existing safety practices of TG. The company operators lack the advanced leak detectors and trained workers to identify chronically leaking components accurately measure the leak rates and make reliable repairs of the leaks.

\subsection{Fugitive emission from distribution network of TG}

TG has been constructed 12,207.38 km pipelines under the ground at different sizes since its date of incorporation, November 20, 1964 [15]. Above ground facilities of TG comprises CGS, TBS/DRS, and industrial/commercial/residential RMS. No compressor station is present in TG Franchise Area. Table 3 shows the gas leakage at different part of above ground facilities of TG. The leak rate in TBS/DRS was the highest amongst others. But leak volume in residential RMS was high (87.36\%) as the number of residential RMS was extremely high. TG was sold 13,600.96 MMCM natural gas in the fiscal year 2011-2012. This study showed that total volume of leaked gas was 281.51 MMCM per year. The percentage of gas leak from gas distribution system of Moldova and different distribution companies of USA were 5.00 and 2.62 respectively [21, 22]. Approximately $2.10 \%$ of sold gas was leaked from above ground facilities of TG. This amount is less than the other distribution companies of the world as this study was considered above ground leaks only. But many reported and unreported leakage were observed in the underground facilities of TG throughout the year. If this un-quantified gas leakage is quantified, the percentage of gas leak will be remarkably high. 
Table 3: CER potential of above ground facilities of TG franchise area.

\begin{tabular}{|c|c|c|c|c|}
\hline Site type & \multicolumn{2}{|c|}{$\begin{array}{rr}\begin{array}{r}\text { Average leak } \\
\text { rate }\end{array} & \text { of Sotal number } \\
\text { of Sites }\end{array}$} & $\begin{array}{l}\text { Leak Volume } \\
(\mathrm{MMCMY}) \dagger\end{array}$ & $\begin{array}{r}\text { Estimated baselin } \\
\text { emission } \\
\left(\mathrm{MTCO}_{2} \mathrm{e} / \mathrm{yr}\right) \dagger\end{array}$ \\
\hline CGSł & 154.00 & 4 & 0.324 & 4.850 \\
\hline Commercial RMS & 2.00 & 10,530 & 11.447 & 171.374 \\
\hline Industrial RMS & 3.00 & 5,938 & 9.486 & 142.024 \\
\hline TBS/DRS $\ddagger$ & 341.00 & 80 & 14.330 & 214.542 \\
\hline Residential RMS & 0.31 & $1,519,124$ & 245.923 & 3,681.906 \\
\hline \multicolumn{3}{|c|}{ Total-Residential } & 245.923 & $3,681.906$ \\
\hline & \multicolumn{2}{|c|}{ Total Non-Residential } & 35.587 & 532.790 \\
\hline \multicolumn{3}{|c|}{ Total } & 281.510 & $4,214.696$ \\
\hline \multicolumn{5}{|c|}{$\begin{array}{l}\dagger \mathrm{L} / \text { min means litre per minute, MMCMY means million cubic meter per year, } \mathrm{MTCO}_{2} \mathrm{e} / \mathrm{yr} \\
\text { means kiloton of carbon dioxide equivalent per year. } \\
\text { ‡ CGS means City Gate Station, RMS means Regulating and Metering Station, TBS means }\end{array}$} \\
\hline \multicolumn{5}{|c|}{ ¥ CGS means City Gate Station, RMS means Regulating and Metering Station, TBS means } \\
\hline
\end{tabular}

\subsection{Economical and environmental effects}

Cathles in 2012 [23] showed that substitution of natural gas reduces global warming by $40 \%$ of that which could be attained by substitution of zero carbon energy sources, wind, solar, nuclear. While the main source of atmospheric methane is natural or agriculture source, a large increase in atmospheric methane from natural gas production. Natural gas burns with fewer carbon dioxide emissions than other fossil fuels, coal and petroleum oil. When un-combusted methane leaks into the atmosphere from wells, pipelines and storage facilities, it acts as a powerful greenhouse gas and decline the benefit of natural gas. Methane in the atmosphere is eventually oxidized, producing carbon dioxide and water. An average molecule of $\mathrm{CH}_{4}$ lasts around eight to nine years before it gets oxidized into carbon dioxide $\left(\mathrm{CO}_{2}\right)$ and water $\left(\mathrm{H}_{2} \mathrm{O}\right)$ [24]. This breakdown accounts for the decline in the global warming potential of methane over longer periods of time. Methane concentrations have more than doubled over the last 150 years [24].

Methane gas emissions have a richer warming effect on climate than has been previously reported. Methane emission in Bangladesh from human activities such as agriculture and from industrial methane production was $103.080 \mathrm{MMTCO}_{2} \mathrm{e}$ during the year 2010 [25]. Table 4 reveals that Russia was the highest methane emitter from gas industry. Among the segments of gas industry, methane emission from gas distribution segments was the highest in USA. Total estimated fugitive emission from above ground facilities of TG was approximately $4.214 \mathrm{MMTCO}_{2} \mathrm{e}$ per year (table 3 ) that was approximately $4.09 \%$ of the total methane emission from human activities. The current weighted average of gas price of Bangladesh was approximately BDT 4.17 per cubic meter. The total volume of gas emitted as fugitive was close to $281.51 \mathrm{MMCM}$ per year whose price is approximately USD 14.67 million. Thus, TG can save approximately USD 14.67 million annually by stopping these emissions. 
Table 4: Worldwide methane emissions [26].

\begin{tabular}{lrrrrrrr}
\hline Country & $\begin{array}{r}\text { Total } \\
\text { MMTCO2e }\end{array}$ & GP & GV & GF & GPG & GT & GD \\
\hline Russia & 319.1 & 131.3 & 0 & 8.5 & 0.5 & 153.9 & 24.9 \\
United States & 259.0 & 172.7 & 0 & 0 & 15.8 & 40.6 & 29.9 \\
Uzbekistan & 83.3 & 34.8 & 0 & 0 & 0 & 40.9 & 7.6 \\
Canada & 55.5 & 23.9 & 2.3 & 0.8 & 5.7 & 10.6 & 12.2 \\
Turkmenistan & 35.3 & 15.7 & 0 & 0 & 0 & 18.5 & 1.1 \\
Venezuela & 30.3 & 13.2 & 9.1 & 3.2 & 3.5 & 0.4 & 0.9 \\
India & 22.6 & 2.6 & 5.2 & 1.8 & 10.5 & 0 & 2.5 \\
Ukraine & 21.8 & 6.5 & 0 & 0 & 0 & 7.6 & 7.7 \\
Argentina & 11.1 & 1.3 & 2.6 & 0.9 & 2.3 & 2.9 & 1.1 \\
Thailand & 3.7 & 0.4 & 0.8 & 0.3 & 1.7 & 0 & 0.5 \\
Colombia & 2.6 & 0.4 & 0 & 0 & 1.7 & 0 & 0.5 \\
China & 2.4 & 0.3 & 0.6 & 0.2 & 0 & 1.1 & 0.2 \\
\hline
\end{tabular}

N.B.: GP, Gas Production; GV, Gas Venting; GF, Gas Flaring; GPG, Gas Processing; GT, Gas Transmission; GD, Gas Distribution.

\section{Conclusion}

Gas leakage from pipelines can be controlled to the acceptable range as it can cause major human injuries, financial losses and environmental pollution. Methane is emitted at the earth surface by a variety of biogenic and non-biogenic sources. The $90 \%$ of atmospheric methane is destroyed in the troposphere and the rest of the sink is due to stratospheric oxidation and an uptake of methane by soils. Approximately 281.51 MMCM gas is releasing on yearly basis from above ground facilities of TG. The company can also get economic benefits annually by capturing and selling leaked natural gas. Additionally, better emissions data are needed to confidently evaluate the risks of natural gas operations to health and climate and to effectively manage operations. TG needs to modify their existing gas regulations by incorporating modern LDAR program to boost gas leak.

\section{Acknowledgement}

This work was supported by the Titas Gas Transmission and Distribution Company Limited for the project of Certified Emission Reductions (CERs) under Clean Development Mechanism (CDM).

\section{References}

[1] DSF, Greenhouse gases, David Suzuki Foundation, December 31, 2013. www.davidsuzuki.org/issues/climate-change/science/climate-changebasics/greenhouse-gases

[2] WC, CDM and its opportunities in Bangladesh, Waste Concern, Bangladesh, November, 2004. 
[3] Plumer, B., Methane Leaks are Undermining the Shale-Gas Boom. Here's How to Fix That, The Washington Post, April 4, 2013.

[4] SLR, Assessing risk and modeling a sudden gas release due to gas pipeline ruptures, July, 2009.

http://www.bsee.gov/Research-and-Training/Technology-Assessment-andResearch/tarprojects/600-699/607AA

[5] Konersmann, R., Kuhl, C., Jorg, L., On the Risks of Transporting Liquid and Gaseous Fuels in Pipelines, BAM Federal Institute for Materials Research and Testing, Berlin, pp. 5-30, 2009.

[6] ADEC, Technical Review of Leak Detection Technologies, Alaska Department of Environmental Conservation, 1999.

[7] Mandal, P.C., Nuruddin, M.M., Begum, R., Miah, M.S. and Mandal, G., Causes of System Loss of Titas Franchise Area and Study of its Reduction Processes, International Journal of Sustainable Agricultural Technology (IJSAT), 3(3), pp. 1-6, 2007.

[8] Mandal, P.C., Gas Leak Detection in Pipelines \& Repairing System of Titas Gas, Journal of Applied Engineering (JOAE), 2(2), pp. 23-34, 2013.

[9] PGNB, Prakitik Gas Nirapatta Bidhimala, 1991 (Revised up to 2003), S.R.O. No. 196-aine/2003, dated: 01/07/2003, Bangladesh, 1991.

[10] Murvay, P.S., and Silea, I., A Survey on Gas Leak Detection and Localization Techniques, Journal of Loss Prevention in the Process Industries, 25(6), November 2012.

[11] J. Liu, J. Yao, M. Gallaher, J. Coburn, and R. Fernandez, Study on Methane Emission Reduction Potential in Chinas Oil and Natural Gas Industry, Tech. rep., April 2008.

[12] Styles, G., Study Sheds Light on the Environmental Impact of Shale Gas, The Energy Collective, October 22, 2013.

[13] IPCC, IPCC Fourth Assessment Report: Climate Change 2007, Intergovernmental Panel on Climate Change, 2007. http://www.ipcc.ch/publications_and_data/ar4/syr/en/contents.html

[14] Bradbury, J. and Obeiter, M., 5 Reasons Why Its (Still) Important to Reduce Fugitive Methane Emission, WRI Insights, May 6, 2013.

[15] TGTDCL, Gas Analysis of Demra CGS, Titas Gas Transmission and Distribution Company Ltd., Dhaka, Bangladesh, September, 2013.

[16] Bylin, C., Cassab, L., Cazarini, A., Ori, D., Robinson, D., and Sechler, D., New Measurement Data has Implications for Quantifying Natural Gas Losses from Cast Iron Distribution Mains, Pipeline and Gas Journal, September, 2009.

[17] Mitchell, C., Sweet, J., A Study of Leakage from the UK Natural Gas Supply System with Reference to Global Warming, Greenpeace (GP), UK, August 1990.

[18] EPA, Methane Emissions from the Natural Gas Industry, U.S. Environmental Protection Agency, June, 1997.

[19] Revkin, A.C. and Krauss, C., Curbing Emissions by Sealing Gas Leaks, New York Times, October 14, 2009. 
[20] Howarth, R.W., Shindell, D. and Santoro, R., Ingraffea, A., Phillips, N. and Townsend-Small, A., Methane Emissions from Natural Gas Systems, Background Paper Prepared for the National Climate Assessment, Reference number 2011-0003, February 25, 2012.

[21] PA, Reducing Lost and Unaccounted for Natural Gas in Distribution, Pennsylvania Government, USA October 15, 2013.

[22] UNFCCC, Reducing Gas Leakages within the Moldovagaz Distribution Network, Republic of Moldova, Version 9, December 10, 2012.

[23] Cathles, L. M., Assessing the greenhouse impact of natural gas, Geochem. Geophys. Geosyst., 13(6), pp. 1-18, 2012.

[24] Schmidt, G., Methane: A Scientific Journey from Obscurity to Climate Super-Stardom, NASA Goddard Institute for Space Studies, September 2004.

[25] WB, Methane emissions, World Bank, 2010. http://data.worldbank.org/indicator

[26] CATF, Methane Emission from the Oil and Gas Sector: Barriers to Abatement and Technologies for Emission Reductions, Clean Air Task Force, March 2013.

http://www.catf.us/resources/publications/view/182 